\title{
LOS ÉXODOS CENTROAMERICANOS 2014-2020. ANTECEDENTES Y CONSECUENCIAS DE LA CARAVANA CON DESTINO A TIJUANA DE 2018
}

THE CENTRAL AMERICAN EXODUSES 2OI4-2020. BACKGROUND AND CONSEQUENCES OF THE 2018 TIJUANA-BOUND CARAVAN

Guillermo Alonso Meneses*

\section{RESUMEN}

Lo que se ha dado en llamar el éxodo centroamericano en el siglo xxi, en realidad está constituido por varias oleadas concentradas entre el 2005 y el 2019. Unas veces atravesando México discreta y clandestinamente y las menos de las veces en caravanas públicas. Lo cierto es que ha habido diferentes episodios protagonizados, entre otros, por menores de edad, como en 2014 y 20I6, por familias como en 2019, caravanas religiosas y otras laicas y politizadas. En este artículo se ofrece un panorama retrospectivo y sintético de los principales episodios, apoyado en estadísticas oficiales, información hemerográfica y material etnográfico. Con un microanálisis de la caravana del 2018 que se "evaporó» en Tijuana.

Palabras clave: Migración centroamericana, México, Estados Unidos, Tijuana, éxodo.

\section{ABSTRACT}

What has been called the Central american exodus in this 2Ist century, in fact was made up of several waves concentrated between 2005 and 2019. Sometimes crossing Mexico discreetly and clandestinely and other times in public caravans. The truth is that there have been different episodes starring minors as in 2014 and 2016, families as in 2019, religious caravans and other secular and politicized. This article offers a retrospective and synthetic overview of the main episodes supported by official statistics, hemerographic information and ethnographic material. With a microanalysis of the 2018 caravan that «evaporated» in Tijuana.

Keywords: Central american Migration, Mexico, USA, Tijuana, exodus.

Recibido 19 de marzo de 2021 y aceptado 30 de abril de 2021

*Profesor-Investigador de El Colef. <gui@colef.mx>. 
$\mathrm{D}$ onald Trump, tras tomar posesión como presidente de Estados Unidos en enero del 20I7, firmó ante las cámaras de televisión la orden de construir un muro en la frontera suroeste con México. Fue un gesto mediático, parte de su «negative political rethoric», que encendía (fueled) las percepciones e imaginarios xenófobos que parasitan a amplios sectores de la sociedad estadounidense. Otra de sus promesas electorales había sido la de incrementar las deportaciones, habló de expulsar a tres millones de inmigrantes, porque desde 1996 el muro y las deportaciones son dos de los principales instrumentos para "controlar» (enforcement) o gestionar la migración irregular. Sin embargo, en los cuatro años de su mandato no alcanzó el millón de deportaciones (ICE, 2O2I).

Las amenazas de Donald Trump, sin embargo, marcaron el rumbo de la política fronteriza para los siguientes años 2017-2020. Un marco de animadversión y conflicto permanente con México y con los flujos internacionales de migración que proceden básicamente de Guatemala, Honduras y El Salvador. Un marco distorsionador sin el cual no se puede entender la crisis caótica derivada de las caravanas y el éxodo masivo de migrantes centroamericanos que inició un ciclo excepcional en el 2014 y culminó en los eventos de grandes magnitudes e impacto mediático a fines del 2018 y en 20I9. Cuando un tsunami migratorio sin precedentes desbordó la frontera sur mexicana y la suroeste estadounidense, y tras atravesar México, se entregaba en Estados Unidos al cruzar la frontera. Este ciclo comenzó a declinar en la segunda mitad del 2019 y se cerró en el 2020 con la pandemia de Covid-I9.

Aguayo (1985) ya habló de éxodo centroamericano, un concepto que se ha retomado recientemente. Sin embargo, la primera erupción significativa del fenómeno en lo que va del siglo xxi tuvo lugar en el 2005 y la primera estadísticamente importante tuvo lugar en el 20I3-20I4. El siguiente episodio relevante fue en el 2016, y cuando en el 2017 las detenciones en la frontera sw estadounidense cayeron a un mínimo histórico propio de la década de los setenta, al igual que había ocurrido en el 20II, volvió a explotar en el 20I8-20I9 con una virulencia sin precedentes. Hasta que en el verano del 2019 el ciclo se interrumpió bruscamente, primero con la rectificación de la política transmigratoria del Estado mexicano de la $4 \mathrm{~T}$ ante las amenazas de Trump y después con la declaración de la pandemia del Covid-i9 en el 
primer cuatrimestre del 2020, que colapsó los flujos migratorios internacionales a nivel global y por ende los que atraviesan México.

Paralelamente, la ciudad de Tijuana, desde finales de la década de los noventa se transformó en la principal ciudad de destino de deportaciones o contraflujos migratorios, que comenzaron a crecer estadísticamente a partir de 1997; posteriormente, a partir del 2002 y finalmente a partir del 2008. En lo que va del siglo xxi se transformó en la ciudad que más inmigrantes deportados recibe de los EE. UU., la capital mundial de la deportación junto con Ciudad Juárez. A continuación, a partir del 2013 cobraron protagonismo unos flujos atípicos y nuevas formas de movilidad migratoria (Alonso, 2019), principalmente desplazados internos de México, haitianos y centroamericanos. La ciudad recibió un contingente de cerca de 20000 haitianos entre 2016 y 2017, así como una caravana de centroamericanos con más de 6000 personas a fines del 20I8. En ambos casos, la intención primera era cruzar a EE. UU. y encontrar formas de regularse, así como evitar la ruta del Golfo que es la más peligrosa y la más utilizada por los centroamericanos.

Este artículo está basado en trabajo etnográfico en Tijuana, revisión hemerográfica y multimedia (ciberetnografía) y de estadísticas oficiales de Estados Unidos y México, del Departamento de Seguridad Nacional o Interior -DHS, por sus siglas en inglés- y el Instituto Nacional de Migración -INMrespectivamente. Triangulando dialécticamente estas tres fuentes, revisadas a partir de referentes teórico-conceptuales con perspectiva histórica, es que se evalúan algunos de los efectos colaterales de la caravana del otońo del 20I8. Por ejemplo, la excepcional escalada de las detenciones de la Patrulla Fronteriza en el 20I9. Para ello, se revisaron algunos antecedentes, como lo ocurrido en la frontera de Estados Unidos con México en el 2014 y la primera oleada de menores de edad y grupos familiares centroamericanos, el antecedente de la "caravana invisible» de haitianos en Tijuana en el 20ı62017 y su destino final. Y se hace un microanálisis de algunos aspectos de la caravana del otońo del 2018 en Tijuana.

La hipótesis que se defiende apunta a que la caravana del otoño del 2018 desencadenó, entre otras consecuencias, un histórico efecto llamada o de ósmosis (empuje, imitación) migratorio, combinado con una mala gestión migratoria en las últimas semanas de la presidencia de Peña Nieto y los primeros ocho meses de la presidencia de López Obrador y la 4-T, en especial 
desde el Instituto Nacional de Migración (encabezado en aquel entonces por un académico especialista en administración pública panista, no en migraciones internacionales, como se nos quiso hacer creer desde la Segob), lo que en parte explicaría la grave crisis migratoria del 2019 y la contraproducente tensión histórica entre México y los Estados Unidos.

\section{ALGUNOS APUNTES HISTÓRICO-CONTEXTUALES}

La relación de México con el fenómeno migratorio centroamericano en el periodo 2000-2020, entre la llegada al poder del PAN y el presidente Fox y la pandemia del Covid-r9 durante el sexenio de López Obrador, fue creciendo tanto en complejidad como en números absolutos, al tiempo que sus políticas y estrategias de gestión de la migración se sumían en la confusión y la contradicción. México; en lo que va del siglo xxi, ha pasado de ser un país fundamentalmente de emigrantes -expulsor-con casi 37 millones de mexicanos y sus descendientes residiendo en Estados Unidos, II millones nacidos en México y de ellos 5 millones en situación irregular (Mexa Institute, 20I9a), a ser un país de migración multidimensional y multidireccional.

Si a fines de la década de los setenta México ya era un veterano país expulsor de inmigrantes, también comenzaba a ser un país de tránsito para los centroamericanos. Una condición que se fue ensanchando en las décadas de los ochenta y noventa debido a las guerras, dictaduras y crisis socioeconómicas que azotaron gran parte de la región, donde la excepción es Costa Rica, y con el siglo xxi se consolidó como país de inmigración o destino (que incluye la inmigración, así como el asilo y refugio en menor proporción), tránsito (con migrantes procedentes del Caribe, Centro y Sur América, África y Asia), además de retorno y deportación o repatriación de connacionales que vivían en Estados Unidos. Esta pluralidad de actores y factores es lo que complejiza el caso de México y lo hace multidimensional. Un caso único y especial en el sistema migratorio mundial.

Los migrantes centroamericanos llevan décadas quejándose de que los coyotes cobran caro y denuncian que cada vez es más difícil atravesar México por todo el peligroso camino hasta la frontera con EE. UU. y, una vez cruzada, tras ser capturados, también se quejan del trato hostil que reciben 
de la migra. La opción de regular la situación en México solicitando asilo o refugio lleva años mostrándose como una opción débil o poco popular, aunque en el 2016 se deportó a I 47 ooo extranjeros, la mayoría de Centroamérica (Semple, 2017). La situación de México es desconcertante, porque al tiempo que anualmente recibe por los puestos fronterizos del norte decenas de miles de connacionales deportados, por el sur deporta o repatria a decenas de miles de centroamericanos y otros extranjeros en situación irregular. Su política inmigratoria refleja la misma intransigencia estadounidense, sin duda inducida por estos, y es el «mismo juego» que se observa entre la Unión Europea con Turquía, Marruecos, Mauritania o Senegal (Alonso, 2016).

\section{ALGUNOS RASGOS CONCEPTUALES E HISTÓRICOS DE LA REGIÓN CENTROAMERICANA}

Para referirme a la subregión integrada por Guatemala, Honduras y El Salvador, evito el término Triángulo Norte de Centroamérica o Centroamericano (TNC), por tratarse de una terminología neocolonial y de inspiración estadounidense (el ICE, la migra, habla de Nothern Triangle Countries, o Países del Triángulo Norte, NTC por sus siglas en inglés) (ICE, 20I8) o la ONU (UNODC, 20I2). Durand (2020) critica ese término con argumentos convincentes. Y es que bajo una abstracción tendenciosa crea una regionalización en más de un aspecto distorsionadora, que ningunea las especificidades socioculturales (políticas, económicas, demográficas, religiosas, etc.) y tiene rasgos neocoloniales estadounidenses y del autoritarismo académico que impone etiquetas que usurpan la autonomía en la autorrepresentación de sujetos y pueblos.

Esa terminología homogeneizadora de TNC ignora tácitamente que Guatemala tiene una población que supera en más de 6 millones de habitantes a la de Honduras y El Salvador, o que el PIB de Guatemala supera en más de 50 mil millones de dólares a los de El Salvador y Honduras, cuando el crecimiento económico regional lleva más de 40 años estancado (Durand y Massey, 20I9; Mexa Institue, 20I9b). Etiquetas como la del TNC despersonalizan a naciones y proyectan una falsa homogeneidad regional. Sin negar, por ello, que puedan compartir características basadas en indicadores agregados y multicausales heterogéneos y que proyectan una coherencia estadística 
distorsionadora, inexacta o acientífica, como, por ejemplo, que las crecientes tasas de asesinatos en Guatemala, El Salvador y Honduras doblan las de Belice, Costa Rica o Panamá (Durand y Massey, 2019: I3).

El flujo migratorio centroamericano que atraviesa México está compuesto mayormente por personas procedentes de la región tradicional de expulsión que conforman Guatemala, Honduras y El Salvador, y en mucha menor medida de Nicaragua, resultando irrelevante desde un punto de vista estadístico - por razones bien distintas en cada caso- la presencia de personas procedentes de Belice, Costa Rica y Panamá. Fue en el periodo I980-2000 que se produjeron cambios significativos, tanto a nivel regional como mundial, al producirse reacomodos en la migración centroamericana a EE. UU. debido a los conflictos intrarregionales. Centroamérica fue un escenario candente de la guerra fría en su expresión revolucionaria/contrarrevolucionaria entre los EE. UU. y la URSS/Cuba. El resultado fue un proceso que, en síntesis, eclosiona y se configura cuando Aguayo (1985) visibiliza el éxodo centroamericano de miles de guatemaltecos que se refugiaron en México, Casillas (I99I) remarca la emergencia de un proceso social migratorio internacional y Castillo (2000) observa un sistema focalizado por políticas públicas pensadas en sus dimensiones de origen, tránsito y destino.

Por otra parte, hubo aspectos que redimensionaron el fenómeno como la migración en "masa» $y$ "forzada», incluso con el componente expulsor medioambiental asociado a huracanes -el Mitch en 1998 o Stan en 2005- o sequías, que son un factor y patrón repetidos en la historia de las migraciones (Petersen, 1979). La historia de los últimos 60 años de esta región está marcada por dictaduras, guerras civiles, conflictos armados, injerencias neocoloniales, desigualdad económica, narcotráfico y violencia de pandillas y el crimen organizado que ha resultado desoladora (Castillo, I983; Pastor, I988; Menjívar, 2000; Torres-Rivas, 20I2; Durand y Massey, 20I9; Hernández, 20I9; Mexa Institue, 2019b).

Al final, aquellos flujos migratorios pos 1980 establecieron las bases de las actuales redes sociales y familiares de migrantes de Centroamérica, así como la inculcación social de la cultura migratoria en el imaginario de estas sociedades. Ya para el año 2017 se estimaba que en Estados Unidos había entre residentes, ciudadanos o descendientes-2 307000 salvadoreños, I 444 ooo guatemaltecos y 940 ooo hondureños. Siguen los nicaragüenses con 
464000 personas y los panameños con 210 000 (Noe-Bustamante, 2019). Los salvadoreños en Estados Unidos pasaron en 45 años de 15717 a 2307 ooo, una diferencia que ilustra el cambio radical habido y la brutalidad de la guerra y las sucesivas crisis (ECLAC, 2006). Y ya a finales del siglo xx tenían importantes redes sociales llenas de vitalidad (Menjívar, 2000).

Por otra parte, sería un error considerar a la región centroamericana en general como un todo homogéneo, no solo por los diferentes ciclos migratorios que conoció cada Estado o la diversidad intranacional en cada uno de ellos, con una población social y económicamente diversa, así como étnica y culturalmente diferente, donde los rasgos y perfiles fenotípicos de indígenas y afros no son aspectos menores, aunque la imagen que se ha proyectado es la de «uniformarla» (triangularla) regionalmente bajo el común denominador de la migración, la desigualdad y la violencia. Pero si en origen la violencia es un potente factor de expulsión, durante el viaje migratorio por México aparecen distintas modalidades de violencia y asaltos que afectan directamente a los centroamericanos, perpetrada por policías, maras, pandilleros locales, el crimen organizado mexicano, que llevan más de 30 años (re)produciéndola (Casillas, I99I; Sánchez, I993; Ruiz, 200I; Cordero y Figueroa, 20II; Izcara, 20I7).

\section{ALGUNOS HITOS MIGRATORIOS ESTADÍSTICOS}

Las corrientes migratorias humanas no siempre dejan huellas estadísticas en el tiempo y el espacio. El año 2000 resultó ser el año donde Estados Unidos registró mayor número de arrestos en su frontera con México: I 643679 eventos de detención. La inmensa mayoría fueron mexicanos y apenas 50 ooo centroamericanos. El primer repunte importante del flujo migratorio centroamericano e internacional en la frontera suroeste de Estados Unidos, según las estadísticas del DHs, ocurrió en el «año fiscal» 2005. Un año fiscal (FY, por sus siglas en inglés) abarca del I de octubre al 30 de septiembre del ańo siguiente. Por primera vez en la historia estadounidense, en el FY 2005 se superó la cifra de Ioo ooo detenciones de no mexicanos en la frontera con México, aunque la mayoría de detenciones fue de connacionales mexicanos: I 023930 sobre un total de I I89 IO8. 
En concreto, se realizaron I54987 eventos de captura de centroamericanos; el año anterior habían sido 65 8I4 y un año después fueron 98 I53. De ellos, eran hondureños 52 760; salvadoreños, 39 308; brasileños, 31 072, y guatemaltecos, 22 593; la presencia de brasileños fue un hito excepcional que nunca más ha vuelto a repetirse. Posteriormente, hubo que esperar ocho ańos para volver a rebasar las Ioo ooo detenciones, mayormente de centroamericanos, cuando en el FY 2013 se hicieron 148988 detenciones (Wu, 2006; СBP, 20I7).

El siguiente hito lo encontramos en el FY 20I4 cuando al final de aquel año en la frontera suroeste de Estados Unidos/Norte de México se realizaron 252600 eventos de detención de centroamericanos, de un total de 47937 I. Por primera vez en más de Ioo años, desde que Estados Unidos tiene registro, los centroamericanos superaban en número a los detenidos de origen mexicano al representar el 52.7 por ciento.

Además, la mayoría de migrantes menores de edad detenidos en la frontera procedía de México hasta el FY 2OI3; a partir del FY 2OI4, México perdió la primacía en ese rubro. Ese año, el país del grupo mayoritario de menores capturados fue Honduras con I8 244 (СBP, 20I7). El número inusual y repentino de menores no acompańados del FY 2014 obligó a internarlos en centros alternativos y provocó una crisis humanitaria e institucional debido principalmente a los reacomodos que debieron hacerse en el interior de Estados Unidos, como los casos de Escondido y Murrieta en el sur de San Diego, California. En ambas localidades -cities- se intentó alojar a los menores migrantes y se produjo un fuerte rechazo local, que entremezcló xenofobia y miedos a un grupo de inmigrantes extranjeros percibidos como potencialmente dañinos (Ruiz, 20I7). Aún hoy ignoramos qué provocó aquel éxodo excepcional de menores de edad.

Seguidamente, en el FY 20I6, por segunda vez en la historia, los migrantes centroamericanos en conjunto superaron en número a los detenidos nacionales de México en la región fronteriza de Estados Unidos con México. El total de las detenciones en la frontera fue de 408 870, cifra menor a la del 2014 en algo más de 70000 detenciones. Pero en esa ocasión los menores no acompañados sumaron 56692 y los individuos que integraban un grupo familiar (Family units) sumaron 77 674. En este aspecto fue otro nuevo récord histórico, ya que superó los 68445 casos del 2014 (CBP, 20I7). 
Paradójicamente, México comenzaba a mostrarse en aquellos años 20I32016 como un país de paso o tránsito migratorio masivo, así como de inmigración y refugio. La opción de regular su situación en México solicitando asilo o refugio se mostró como una opción real para los centroamericanos, aunque en el 2016 México deportó a I47 000 extranjeros, la mayoría de Centroamérica (Semple, 20I7). Por otra parte, la estrategia de movilidad y cruce familiar y la presencia de menores «solos» en el flujo centroamericano se mantuvo y aumentó. Durand y Massey han reparado en la nueva estrategia de los últimos ańos de las familias centroamericanas que, aunque son un colectivo pequeño respecto al resto del flujo -salvo en el año 20I9-, destacando que su nuevo objetivo es buscar refugio, no trabajos (2019: 13).

Entre 2014 y 2019, excepto en el 2015, todos los demás años fiscales, el colectivo de detenidos mexicanos ha sido superado por el colectivo de «extranjeros no mexicanos». Denominados отм u Other Than Mexican, según la terminología oficial estadounidense, y que suelen ser principalmente guatemaltecos, hondureños y salvadoreños. Pero en el 20I9, por primera vez en más de Ioo años, los nacionales de Guatemala (265 129) y Honduras (254 56I), ambos sumaron el 60\%, superaron a los detenidos procedentes de México (I69 536) en la frontera estadounidense del suroeste, sobre un total de 851 508 detenciones (Свр, 2017; Guo, 2020: 5). Esta evidencia estadística, a partir de registros del DHs estadounidense, demuestra que algo había cambiado en el sistema migratorio de Centroamérica y en los países de origen, lo cual incumbe a México.

Los sectores de la Patrulla Fronteriza donde se realizó el mayor número de detenciones de centroamericanos y nacionales de otros países, отм, fueron Rio Grande Valley con 309295 o el 45\% y El Paso con I66 960 o el 24 por ciento. Ambos sectores sumaron el 70\% de las detenciones (Свр, 2019). Es decir, el flujo migratorio centroamericano del periodo 20IO-2020 cuando se desplaza dibuja una "Y», una bifurcación que delinea dos macrorrutas principales bien delimitadas. Una que corre paralela al Golfo de México para llegar al arco formado por las ciudades fronterizas de Reynosa y Matamoros, lo que podemos considerar como la ruta histórica o clásica, y otra que discurre por Sinaloa y Sonora junto al Pacífico, para cruzar entre Nogales y Sonoyta o desviarse antes a El Paso, tras haber cruzado por el Estado de México, por el rumbo de la estación de Lecherías (Baltazar, 20I4), 
a sabiendas de que sobre el terreno las microrrutas alternativas son las que conforman las macrorrutas; por ejemplo, la del Golfo puede discurrir -y cito solo dos- por el eje Villahermosa, Xalapa, Tampico, Matamoros o por la carretera Panamericana desde la Ciudad de México, el valle del Mezquital, la Huasteca, Monterrey y Nuevo Laredo.

\section{CARAVANAS, NEOMOVILIDADES MIGRATORIAS Y PATRONES DE CRUCE 2014-2019}

Las caravanas, como «nueva» estrategia de movilidad centroamericana, dentro del espectro de neomovilidades migratorias (Alonso, 2019), es una idea que es necesario relativizar e historiar. En el verano de 1998, entrevistando a un inmigrante salvadoreño instalado desde hacía años en Ciudad Victoria, Tamaulipas, anoté un detalle en medio de la conversación que siempre me llamó la atención, pero recién la retomo ahora, más de 20 años después. Me dijo que cuando vivía en Estados Unidos -Houston, Texas, en la década de los ochenta-, él y otros compatriotas, que en vacaciones viajaban a El Salvador en automóviles por la carretera Panamericana, se ponían de acuerdo para viajar en grupo "formando una caravana» y así defenderse mejor de las extorsiones y «rapiña» de las policías y autoridades mexicanas. Por esos mismos años, la ruta sur/norte preferida de los centroamericanos era la del Golfo de México hasta Matamoros, tal como lo señala en un estudio pionero Sánchez (1993), donde ya se constatan, por una parte, abusos de policías y animadversión xenófoba, y por otra el apoyo de la Iglesia y de organizaciones cercanas (xenofilia). Curiosamente, en un clima donde se temía al terrorista comunista centroamericano, los nicaragüenses tenían más posibilidades de recibir asilo que los salvadoreños u hondureños.

Cruz de Echeverría (20I4), como parte de su investigación, acompañó una caravana de migrantes mexicanos desde Laredo en Texas hasta Jalpan de Serra, en la Sierra Gorda de Querétaro; la principal razón de esta caravana era buscar seguridad (2014: 63-69). De hecho, el INM acompañó a esta caravana en el periodo navideño del 2019 en su cruce por Nuevo Laredo, como parte del Operativo Invierno del Programa Paisano 2019 (INM, 2019). Esto ya habla que la estrategia de viajar en caravana de norte a sur está apoyada por el gobierno mexicano. Esta caravana está auspiciada y organizada por 
la asociación civil «Migrantes Unidos en Caravana» y lleva organizándose desde el año 2007 (otras fuentes hablan del 2009) y su destino final está en Jalpan de Serra, Querétaro, tras atravesar los estados de Tamaulipas, Nuevo León, Coahuila y San Luis Potosí (Cruz de Echeverría, 20I4; INM, 20I9).

Tenemos entonces que en la cultura de movilidad entre los migrantes está arraigada la estrategia de viajar acompañado o en grupo, en caravanas, y que las primeras caravanas de centroamericanos históricamente cruzaron México de norte a sur en autos y por vacaciones. Sin negar que las caravanas que hasta hace poco entraron en México por la frontera sur tienen una historia y naturaleza propia o no viajaban en sus propios autos. De hecho, estas caravanas procedentes de Centroamérica con cierto grado de organización hay que rastrearlas a partir del 2006, cuando surge el Movimiento Migrante Mesoamericano (MMM). Este colectivo organiza a activistas comprometidos con buscar a migrantes desaparecidos en su recorrido por México, la mayoría de ellos centroamericanos, pero también de México o Estados Unidos.

El ммм a partir del 2008 confluyó en sus intereses con la Caravana de Madres, un colectivo de mujeres sobre todo de Honduras, vinculado a sus iglesias en origen, de ahí que su iniciativa de venir en grupo a México para reclamar a sus familiares desaparecidos se llamara Viacrucis Migrante. Esta iniciativa, a su vez, recibió el apoyo de las casas de refugio de la Iglesia católica mexicana (Varela, 20I3, 20I6). Sin duda, este es el antecedente que sirvió para inspirar las modalidades de caravanas que surgirán especialmente a lo largo del 2018 y el 20I9. Pero en años anteriores ocurrieron otros fenómenos que no podemos perder de vista.

Una estrategia inédita en la historia de la migración que atraviesa México saltó a la luz pública a finales de mayo del 20I6, cuando comenzaron a llegar a Tijuana decenas de migrantes africanos de países como Guinea Conakry o la República Democrática del Congo (no confundir con la República de Congo o Congo-Brazzaville) y comenzaron a esperar frente a la garita de San Ysidro para solicitar asilo en EE. UU. En ese espacio, transitado por decenas de miles de peatones diariamente, coincidieron con algunas familias del interior de México desplazadas por la violencia y que desde días atrás también aguardaban en la puerta para buscar asilo en Estados Unidos. Pero, sorprendentemente, comenzaron a llegar migrantes haitianos procedentes de Brasil y que habían hecho el recorrido por vía terrestre a través de Cen- 
troamérica. El fenotipo afro o, si se prefiere, la piel negra o con un marcado fototipo melanoso, los delataba en una ciudad que solo conoce a los turistas afroamericanos del sur de California, que suelen vestir-según el estereotipocon bermudas, camisetas de la NBA y gorras de raperos.

Los africanos habían cruzado previamente el Atlántico hasta Brasil y los haitianos habían salido de su país tras el terremoto del 2010 y residido hasta entonces en áreas metropolitanas como la de Sao Paulo, Brasil. Posteriormente, africanos y sobre todo haitianos salieron de Brasil rumbo al norte, unos meses antes de comenzar los Juegos Olímpicos de Río de Janeiro en agosto del 20I6. Cruzaron por Ecuador, entraron a Centroamérica por el Darien -con tramos que solo se hacen a pie- en la región fronteriza de Colombia y Panamá, para seguir por Costa Rica, Nicaragua, El Salvador y Guatemala. Esta última, una ruta que estaban siguiendo algunos contingentes numerosos de cubanos desde años atrás. Entraron a México por Chiapas tras varios meses de viaje. Según Coello (2019), el desplazamiento implicó tres meses en promedio y lo invertido osciló entre 3000 y 5000 dólares; estas cifras son coherentes con lo indagado en mis entrevistas en Tijuana, donde, asumiendo que saber la cifra exacta es imposible, se acercaba a la de 3000 dólares.

Se estima que a partir de mayo del 2016 y tras varias semanas llegaron a Tijuana cerca de $\mathbf{2 2}$ ooo haitianos y varios centenares de africanos subsaharianos, desbordando los servicios de acogida oficiales y de la sociedad civil. Todos llegaban en calidad de solicitantes de asilo o refugio, pero sin medios para resistir las semanas de espera, y pronto necesitaron el apoyo y la solidaridad de centros como el Desayunador del Padre Chava, Casa del Migrante, el albergue del Templo Embajadores de Jesús y organizaciones e iglesias estadounidenses que cruzaban la frontera a diario con comida y otras ayudas. De hecho, las filas de espera para tramitar millares de solicitudes de asilo o refugio duraron meses, hasta entrado el 20I7, cuando Donald Trump ya había tomado posesión de la Presidencia. Los millares de haitianos -mujeres, menores y hombres- que hablaban creole y francés o algo de portugués colapsaron la limitada capacidad de recepción y procesado del DHs, especialmente del свP у CIS (Citizenship and Immigration Service), por las complicaciones idiomáticas. Por eso se hizo necesario el envío de 
personal de refuerzo de otros sectores, especialmente con conocimientos del idioma francés.

Baker (20I7) o el ICE (20I8) concluyen que en el FY 2016 se deportaron 6377 haitianos mientras que, en el FY 2017, se deportó a 8057. Según estas fuentes, los haitianos totalizaron I4 434 deportaciones en dos ańos. Sin embargo, Katherine Witsman llega a un recuento superior, al detectar que Haití fue el quinto país con mayor número de personas declaradas inadmisibles en los ańos 2016 y 2017 con 6974 y 992I casos, respectivamente, para totalizar I6 895, solo superados por México, Canadá, Cuba y Guatemala (2019: 7).

Esta última cifra de I6 895 haitianos deportados resulta más coherente con los números que se barajaron en México. En la comunidad haitiana que aguardaba en Tijuana, pronto los primeros que habían pasado a realizar trámites y no habían regresado llamaban a Tijuana para comunicar a sus compatriotas que habían sido deportados a Haití. Poco a poco, los que quedaban fueron desistiendo de presentarse en Estados Unidos y optaron por permanecer en México; se estima que entre 4000 y 5000 haitianos residen en Tijuana (la mayoría) y Mexicali. Evidentemente, la «invisible» caravana haitiana y las posteriores deportaciones constituyen un caso excepcional, una singularidad en la historia de la migración de paso en México y de la frontera México-Estados Unidos.

\section{LA CARAVANA CENTROAMERICANA DEL OTOÑO DEL 2018 EN TIJUANA}

El germen de las caravanas en dirección sur-norte se fraguó al calor de los viacrucis migrantes, con un significativo componente hondureño, pero no llegaban a EE. UU. (Varela, 2013, 2016). El Viacrucis Migrante se celebró durante años al llegar la Semana Santa católica, coordinado en México por Irineo Mújica, de Pueblo Sin Fronteras, y Gina Garibo, coordinadora de proyectos en México de la misma organización. La primera caravana en lograr llegar a la frontera con EE. UU. tras cruzar México fue en el 2014 y había iniciado en Tenosique (Semple, 20I8a). El gobierno mexicano en el sexenio de Peña Nieto había comenzado a ofrecer permisos temporales de tránsito de 20 días para que el migrante pueda salir del país o de 30 días para meter una solicitud formal de asilo o de inmigrado regulado en México. Los 
haitianos las habían utilizado en el 20I6. Asimismo, en el 2017 fueron 14600 personas, la mayoría de Honduras, quienes solicitaron asilo en México, una cifra que duplicaba la del 2016 (Semple, 20I8b).

Por otra parte, a la luz de la experiencia haitiana, que cruzó México de sur a norte por la ruta más larga sin llamar la atención hasta que se presentó en Tijuana, las dos caravanas organizadas durante todo el 2018 tuvieron dos génesis y dos patrones bien distintos. La primera inició en la primavera del 20I8, como en años anteriores vinculada a la Semana Santa y el Viacrucis Migrante, entró en México con algo más de un millar de centroamericanos. Partió de Tapachula el 25 de marzo y nadie imaginaba la minicrisis que se avecinaba. Una semana después, Donald Trump la calificó de peligro y amenazó con llevar el ejército a la frontera con México (Hirschfeld y Sullivan, 20I8).

Las declaraciones del presidente Trump resonaron mediáticamente por medio de tweets alarmistas: "las caravanas vienen en camino», o «se están volviendo más peligrosas» (Semple, 20I8a). La animadversión sorprendió porque el millar de personas que la integraban, en su mayoría mujeres y menores de edad, estaban acampados en un complejo deportivo de Matías Romero, Oaxaca, tras una semana de viaje y su imagen era pacífica. Pero el I de abril Trump tuiteó que había «manadas de migrantes peligrosos de camino a la frontera» y amenazó a las autoridades mexicanas con endurecer las negociaciones del TLCAN que meses después dio lugar al T-MEC. La caravana pareció diluirse en pocos días y el gobierno mexicano negó haberla presionado (Semple, 20I8b). Pero también días después la Guardia Nacional estaba acampada en el Condado de Starr, Texas, al noroeste de las ciudades de Reynosa/McAllen (Fernández, 20I8). Finalmente, el 30 de abril llegaban unas 400 personas a Tijuana y se presentaron en el Chaparral, el nuevo Puerto de Entrada que complementa al histórico de San Ysidro, acamparon y aguardaron semanas para ser atendidos en sus solicitudes de asilo (Ximénez, 20I8).

Con estos antecedentes de principios de año, sorprendió contemplar la génesis de la caravana de migrantes hondureños de aproximadamente 1500 personas que salió literalmente caminando rumbo a EE. UU. de la ciudad de San Pedro Sula, Honduras, el viernes I2 de octubre del 2018 (Semple, 20I8c). Un día en que se cumplían 526 años de la arribada de Colón al Ca- 
ribe y que, al contrario de las asociadas al viacrucis, esta era laica. A pesar de las presiones del gobierno de Trump que amenazó con cortar la ayuda a Honduras, El Salvador y Guatemala, en unos días la caravana ya transitaba por Guatemala con 4000 personas, rebasando los bloqueos carreteros de la policía o desoyendo los llamamientos de sus gobernantes para que desistieran (Semple, 20I8d).

Otro elemento nuevo es que era seguida por una amplia cobertura mediática internacional de dimensiones inéditas, en lo que parecía la crónica de un éxodo anunciado. El recorrido de la caravana prácticamente fue retransmitido en directo y de hecho la televisión mostró en vivo su llegada a la frontera con México el in de octubre, el cruce de los puentes sobre el río Suchiate y cómo tras desbordar a las autoridades mexicanas forzaron su entrada caótica en México, tanto por el puente en Tecún Umán como por el río Suchiate. Las imágenes se vieron en Estados Unidos, difundidas por los medios conservadores, y crisparon a las autoridades estadounidenses.

El comisionado del свp, Kevin K. McAleenan, en rueda de prensa con el general del Comando Norte de Estados Unidos (Northcom), Terrence O'Shaughnessy, lo que da idea de la «exageración» de la puesta en escena, declaraba el 29 de octubre: «A partir de esta tarde, continuamos rastreando a un gran grupo de aproximadamente 3500, viajando a través del sur de México con la intención declarada de llegar a la frontera de los EE. UU. Este grupo está cerca de la frontera de Chiapas/Oaxaca en el sur de México. También conocemos un segundo gran grupo de migrantes en el cruce fronterizo de Ciudad Hidalgo entre Guatemala y México. Las estimaciones de tamaño para el segundo grupo también son de alrededor de 3000» (traducción propia) (CBP, 20I8). Y se oficializaba el envío de efectivos, hasta completar varios miles, a la frontera con Texas, que es por donde se estimaba que arribaría la caravana (Hirschfeld, 20I8).

El recorrido desde Ciudad Hidalgo/Tapachula hasta Tijuana formalmente podría recordar al de los haitianos del verano del 20I6. Sin embargo, mientras los más de 20000 haitianos cruzaron discretamente México de sur a norte en autobuses de línea, el río humano de migrantes hondureños, guatemaltecos y salvadoreños - las tres nacionalidades principales- pronto dejó de avanzar a pie, al recibir numerosas muestras de solidaridad. Esta ayuda, unas veces parecía sincera de la sociedad, otras veces parecía «sos- 
pechosa» por proceder de autoridades municipales y estatales, sumamente interesadas en que transitaran lo más rápido posible por su jurisdicción. El gobernador panista de Veracruz intentó poner autobuses a disposición del éxodo centroamericano. El dictum de Maquiavelo, «enemigo que huye [o que quiere seguir de largo], puente de plata», lo pudimos vislumbrar por todo el recorrido hasta llegar a Tijuana.

Las más de las veces subidos a vehículos como camionetas, tráileres o autobuses, retén tras retén, distintos ramales de la caravana atravesaron Chiapas, Oaxaca, Veracruz y se plantaron en Ciudad de México. Desde allí salieron rumbo al norte y tras pasar por Querétaro y Guadalajara enfilaron las autopistas de Nayarit, Sinaloa y Sonora, plantándose el primer contingente del colectivo LGTBI+ los primeros sobre el Io de noviembre. Visto en retrospectiva, hubo una extrańa urgencia para que transitaran por México velozmente y llegar a la frontera norte, a pesar de las amenazas de Trump.

$\mathrm{El}$ I3 de noviembre, tras un mes desde que había iniciado el i2 de octubre, varios centenares irrumpieron en Tijuana con un ímpetu propio de las masas que se movilizaban cuando las fiebres del oro en California o Alas$\mathrm{ka}$, y deambularon por las vías y avenidas con una arrogancia pocas veces antes vista entre migrantes, que generalmente buscan mantener un perfil bajo y pasar inadvertidos, optando por «la clandestinidad» (Alonso, 200I, 2013); históricamente habían recorrido México anónima y «discretamente» (Casillas, 2006). Llegaban desde Mexicali, en cuyo trayecto hubo algunos accidentes y un migrante atropellado, y cientos de ellos se enfilaron hacia la delegación de Playas de Tijuana, la esquina noroeste de México, donde la barda fronteriza se adentra en el océano Pacífico, junto al faro y el parque de La Amistad, con su contraparte estadounidense.

Este espacio «binacional» lo inauguró Paty Nixon en I97I y aún está el árbol que sembró como símbolo de la amistad entre ambas naciones y de rechazo a las fronteras que separaban a los pueblos como el muro de Berlín; aquel año de la inauguración ardía la Guerra Fría en Vietnam. Hoy la cara suroeste del Friendship Park parece un campo de concentración, es esa frontera de un mundo Gulag de la que habló Salman Rushdie (2003). Por casualidades de la historia, fue uno de los lugares elegidos por algunos grupos de migrantes centroamericanos para culminar la etapa final del trayecto mexicano, antes de intentar entrar en los Estados Unidos de América. 
La caravana había recorrido más de $4000 \mathrm{~km}$ desde San Pedro Sula y los últimos kilómetros antes de llegar al mar los hicieron colapsando el tráfico bajo el fuerte sol del mediodía, al transitar invadiendo el carril derecho para automóviles, en un horario donde cientos de padres y madres de familia van a buscar a sus hijos a los diferentes colegios y preparatorias que hay cerca.

Precisamente en la barda-muro de la playa se encaramaron algunos jóvenes, unos para tomarse un selfie desde lo alto, otros para otear los rascacielos del Down Town de San Diego y una minoría de ellos saltó a Estados Unidos y regresó a México de vuelta, para provocar al grupo de patrulleros fronterizos que atónitos vigilaban a una distancia prudente. La experiencia de cruzar México de sur a norte los había empoderado, lo que hizo que más de uno, sin duda obnubilados por el entusiasmo, se comportara altiva y provocativamente en los espacios públicos. El juego duró varias horas, pero tuvo consecuencias contraproducentes, porque calentó los ánimos con las autoridades estadounidenses y con una minoría de vecinos tijuanenses. La policía municipal tijuanense, como tantas otras veces, no impidió aquel ingenuo e irreflexivo acto de provocación; no se sabe si por exceso de prudencia, falta de profesionalidad o negligencia disfrazada de tolerancia.

Las declaraciones de uno de los migrantes de la caravana hechas a una reportera local sintetizan las expectativas y el anhelo de la mayoría de ellos: «Hay que esperar a ver si Trump se toca el corazón y nos da el pase para salir adelante, no para quedarme para toda la vida, solo unos años para salir adelante y poder trabajar» (Sánchez, 20I8).

Al llegar la noche, cuando varios grupos se decidían a pernoctar en la playa, hubo un conato de conflicto y se vivieron momentos de tensión por la queja in situ de un grupo de vecinos indignados. La policía tuvo que interponerse entre los vecinos y los integrantes desconcertados de la caravana, y el Ayuntamiento decidió reacomodarlos en albergues. Horas después cedieron el campo deportivo Benito Juárez, colindante con la Vía Internacional y la Avenida 5 de Mayo, en la Zona Norte, donde se levantó el campamento improvisado a escasos metros de la frontera y cerca del histórico sitio del Bordo. Durante los siguientes días y semanas estuvieron llegando diferentes "partes» de las caravanas a Tijuana, porque entre Tapachula y Ciudad de México la caravana principal se fue fragmentando, así como otros grupos que cruzaron la frontera posteriormente. 
Por fuera del campo deportivo, junto a la avenida Internacional, la Marina Armada de México montó una cocina. Se instalaron dos depósitos de agua que pronto fueron insuficientes y fueron sustituidos por otro de mayores dimensiones. Durante días, la vida para la mayoría de los alojados en el campamento, familias o grupos de jóvenes, era deambular por el Centro de Tijuana. Tanto al interior como al exterior se producían movimientos que denotaban organización. Algunos integrantes de la caravana recibían apoyo económico de sus familiares residentes en Estados Unidos e iban a cobrar los envíos a una tienda comercial de Elektra de la calle Segunda, que dista unas cuatro cuadras del campamento en la Unidad Deportiva Benito Juárez. En distintas horas del día, por fuera se formaban improvisadas filas de jóvenes cuando se organizaban repartos de comida o de ayuda de distintas organizaciones. Mamás o jóvenes parejas con sus hijos pequeños eran entrevistados a pie de calle por periodistas. Al interior seguía una vida cotidiana de campamento y se producían reuniones en torno a líderes y coordinadores.

Sin embargo, el episodio más impactante tiene fecha y hora exacta. El domingo 25 de noviembre del 2018 a las I2:I5. A esa hora cruzaba a pie por el largo andador que lleva a la nueva garita del Chapatal, cuando se formó un revuelo entre los soldados y funcionarios del INM que vigilaban el acceso. Por el cauce del río Tijuana descendía una muchedumbre, integrantes de la caravana centroamericana, mayores y menores de edad. Llamaba la atención una gran bandera blanca, y otras de Honduras y Guatemala. Los funcionarios del INM dijeron que corriéramos porque seguro que iban a cerrar la línea en EE. UU. El lado mexicano del Chaparral quedaba cerrado para quien no fuera ciudadano estadounidense. Varias decenas de personas atravesamos los cientos de metros que nos separaba de la entrada a Estados Unidos. Pero al llegar los portalones estaban ya cerrados y custodiados por agentes de México.

Atrapados frente al umbral de la línea, había decenas de ciudadanos estadounidenses y mexicanos. Los agentes del СвP estaban tras las imponentes e inexpugnables puertas de rejas bien trancadas. Los centroamericanos avanzaban por el canal del río que está a un lado del andador del Chapatal y unos pocos saltaron al interior, creyendo haber entrado en Estados Unidos. Granaderos antidisturbios y personal del INM, de migración mexicana, los detuvieron. La prensa dijo al día siguiente que serían deportados. Cuando 
se calmó la situación dentro, porque el grueso del grupo continuó por la canalización del río, decidieron dejarnos entrar y pasar el control de visas tanto a estadounidenses como a mexicanos $\mathrm{u}$ otras nacionalidades y cerraron definitivamente.

Atrás, parte de los centroamericanos se dirigieron hacia los carriles de cruce de autos, y otros algo más allá, a la altura de la vía férrea. En aquellos momentos fueron cancelados con unas tapias móviles de acero a modo de altos escudos los carriles de cruce para autos. La línea estuvo cerrada hasta algo más de las 5 de la tarde. Nunca antes en la historia de Tijuana la línea fronteriza había sido asaltada por una multitud de miles de personas, ni se había cerrado de esa manera la frontera estadounidense. Fueron disueltas por las fuerzas de seguridad estadounidenses, sobre todo en el cauce del río a la altura del Bordo y por las vías del tren a los pies de la colonia Libertad. En los siguientes días unas 2000 personas lograron cruzar en forma de grupos pequeños y los miles restantes se dispersaron por la frontera entre fines del 2018 e inicios del 20I9. Seguramente cruzaron la frontera y se entregaron

\section{COMENTARIOS FINALES E (IN)CONCLUSIONES}

Los incidentes del domingo 25 de noviembre del 2018 anudan desesperación y organización, actos irreflexivos y actuaciones contundentes, audacia y violencia. Sea como fuere, supuso el principio del fin de aquella caravana de migrantes. Cuatro días después, el jueves 29 descargó una tormenta sobre Tijuana y llovió intermitentemente todo el día. El campamento se inundó en gran parte y el frío apretó en la noche. Las autoridades locales y federales, con el INM, decidieron el viernes 30 el traslado a un recinto para eventos denominado El Chapetal, a más de 15 kilómetros. El I de diciembre tomó posesión de su cargo el presidente López Obrador. Aunque al principio más de un millar de integrantes aceptaron de mala gana el traslado, pronto hubo descontento. El 3 de diciembre se produjo un cruce masivo de más de 250 personas cerca de playas y ya se comentaba en la prensa local que estaban dejando El Chapetal y abandonando Tijuana (AFN, 2OI8a; AFN, 2OI8b). Hoy sabemos que mientras ocurría este episodio frente a San Diego, en los meses de octubre, noviembre y diciembre fueron detenidos 100 ooo centroame- 
ricanos por los sectores de Texas y Arizona, que aprovecharon que la plaza de Tijuana estaba «caliente», por utilizar el argot de polleros y narcos, para cruzar por zonas menos expuestas mediática y policialmente.

En enero, febrero y marzo del 2019 se siguieron produciendo algunos cruces masivos por Playas de Tijuana, aunque ahora sabemos que el flujo por la frontera de Texas se estaba incrementando con cientos de miles de migrantes guatemaltecos, hondureños y salvadoreños que cruzaban con una intensidad jamás vista por los sectores de Río Grande, El Paso, Tucson y Yuma. La región Tijuana/San Diego quedó estadísticamente como un referente marginal. El Is de febrero de 2019 Trump declaró la Emergencia Nacional en la frontera ante el auge de las detenciones, pues de octubre a enero se hicieron casi 300 ooo detenciones. El nuevo presidente, Joe Biden, dejó sin efecto aquella declaratoria de emergencia dos ańos después, en febrero del 202I.

Pero aún faltaba la gran avalancha de los meses de marzo, abril, mayo, junio y julio durante las cuales se hicieron más de 450 ooo detenciones. En el primer semestre del 2019 las detenciones en la frontera se duplicaron respecto al 20I8, la mayoría guatemaltecos y hondureños, marcando -insisto en ello- un hito histórico excepcional y sin precedentes. Los factores disruptivos en el flujo migratorio sur/norte aportado por los centroamericanos entre el 20I4 y el 20I9, así como por los haitianos y algunas nacionalidades como Cuba, la India o República Democrática del Congo, rompieron algunos patrones y tendencias que habían sido hegemónicos a fines del siglo xx y principios del xxi (Castillo, Lattes y Santibáñez, 1998; Alonso, 2003; Casillas, 2006).

Hasta abril del 2019 hubo otras caravanas, alguna con 3000 personas. Las primeras medidas de la $4 \mathrm{~T}$-desde Gobernación y el INM- fueron improvisadas, desafortunadas y contraproducentes, porque prometieron documentos de identidad, posibilidades de trabajo o facilidades de tránsito sin contrapartida alguna. Esta generosidad imprudente por insostenible tuvo un «efecto llamada» de potenciales migrantes desesperados; no solo fueron centroamericanos, sino también cubanos y de diferentes estados africanos. Donald Trump acabó presionando y amenazando a México con tomar represalias por una política «buena onda», pero negligente o irresponsable en la gestión del tránsito migratorio. Unas veces amenazó con cerrar la frontera, otras con rechazar el T-MEC (el nuevo TLCAN). Y la última medida llamativa 
fue la de ordenar que los grupos de familiares y de menores de edad detenidos por la Patrulla Fronteriza fueran llevados a las ciudades santuario para que colapsaran los sistemas de acogida solidarios.

El México sumido en la esperanzadora 4 T atravesó en el 2019, en cuanto al manejo del fenómeno migratorio se refiere, una crisis multisistémica. Las denominadas caravanas supusieron un reto inédito en la gobernanza de los migrantes en tránsito. Pareció como si en México no hubiera especialistas en migración y, por tanto, tampoco asesoría especializada y medidas eficaces para encauzar este problema. Un problema que Donald Trump convirtió en valiosa munición en la campaña electoral del 2020 .

Las principales soluciones que se manejaron desde la Secretaría de Gobernación y el INM, además de inviables a corto plazo, lo que demuestra la ineptitud, llevan décadas apuntándose: inversiones en los países de origen que rompan la desigualdad económica endémica y restituyan un tejido sociocultural deteriorado. Tal como reconocieron las autoridades estadounidenses oficialmente en el 20I6, con aquella presencia inusual de menores viajando sin familiares ni tutores que suponía un reto inédito, y recordemos que era el último año de la administración presidida por Barack Obama -prácticamente restaban dos meses y medio para finalizar su mandato-: "We are determined to treat migrants in a humane manner.» Al tiempo que se reconocía que cualquier solución a aquel flujo migratorio pasaba por la inversión a largo plazo en la región centroamericana y no en muros fronterizos: «Walls alone cannot prevent illegal migration. Ultimately, the solution is long-term investment in Central America to address the underlying push factors in the region» (DHS, 20I6).

A partir del año 20I7, la administración del presidente Donald Trump dio marcha atrás y desautorizó ese enfoque centrado en ser respetuosos en el tratamiento de las y los migrantes y la inversión en origen, al privilegiar discursivamente los muros y la seguridad fronteriza; y por paradójico que parezca, solo en febrero del año 2020 -año de elecciones presidenciales en Estados Unidos- se promovió una reunión de alto nivel internacional para recaudar fondos para el desarrollo de Centroamérica. Un enfoque apoyado por el gobierno mexicano de López Obrador y la 4-T. La irrupción de la pandemia por Covid-ı9 desbarató aquella iniciativa. 
Por otro lado, la llegada masiva a Tijuana en 2018 de varios miles de centroamericanos, principalmente hondureños, provocaron algunos episodios tachados de xenofobia, manifestaciones de racismo, pequeños enfrentamientos, malestar y otras tensiones sociales, tanto en redes sociales como en diferentes lugares de la ciudad. Sin embargo, las muestras de solidaridad y apoyo fueron mayoritarias. En mi opinión, se trató de actitudes de rechazo por aporofobia (rechazo del pobre) (Cortina, 2017), más que por fobia o rechazo al extranjero, pues los municipios de Tijuana y los vecinos de Rosarito y Ensenada son donde mayor número de extranjeros hay en México, ciertamente estadounidenses. Y durante aquellos días solo un joven integrante de la caravana fue asesinado en extrañas circunstancias en la Zona Norte.

Finalmente, la pandemia por Covid-ı9 declarada en el 2020 colapsó la vida cotidiana, el comercio y la movilidad humana a nivel mundial. Los flujos migratorios han continuado, pero su caudal e intensidad se redujo. El tiempo dirá si la caravana de hondureños que fue reprimida en Guatemala en enero del 202I, pocos días antes del inicio del mandato de Joe Biden, fue el final de un periodo o el inicio de otro, en cuanto a las nuevas dinámicas y neo-movilidades de las caravanas de migrantes centroamericanos. Habrá que esperar a ver si los huracanes de finales del 2020 que asolaron la región y la crisis de la pandemia que aún se agudiza en el 202I concentrarán la suficiente energía para provocar un éxodo descomunal y masivo como el del 2019 o caravanas como las del 20I8. Todo apunta, sin embargo, dicho a modo de hipótesis prospectiva, a que el éxodo centroamericano continuará sin llegar a las cifras excepcionales del 2019, pero en la línea de 2018, que son similares a la del año pandémico del 2020.

\section{REFERENCIAS}

AFN. Agencia Fronteriza de Noticias (2018a). «Saltan» 270 hacia EU; aumentan alambrado. Tijuana, 3 de diciembre. <http://www. afntijuana.info/informacion_general/90353_saltan_270_hacia_eu_aumentan_alambrado\#ver_nota>.

AFN (20I8b). Confirman: No saben el paradero de miles. Tijuana, 3 de diciembre. <http://www.afntijuana.info/informacion_gene- 
ral/90354_confirman_no_saben_el_paradero_de_miles\#ver_ nota>.

Aguayo, S. (1985). El éxodo centroamericano. México: Sep.

Alonso, G. (200I). Migra, coyotes, paisanos y muertitos: sobre la analiticidad y el sentido de ciertos factores de la migración clandestina en la frontera norte. El Bordo, 7(4). Hay versión electrónica. <http:// www.tij.uia.mx/elbordo/>.

Alonso, G. (2003). Human Rights and Undocumented Migration along the Mexican-U.S. Border. UCLA Law Review, SI(I), octubre, 267$28 \mathrm{I}$.

Alonso, G. (2013). El desierto de los sueños rotos. Detenciones y muertes de migrantes en la frontera México-Estados Unidos I993-2013. Tijuana: El Colef.

Alonso, G. (2016). Las fronteras africanas de España-Unión Europea y la crisis de los cayucos en 2006. En G. Alonso (ed.). Fronteras simbólico-culturales, étnicas e internacionales. Su impacto en la vida de las gentes. México: El Colef, 225-267.

Alonso, G. (2019). La antropología de las migraciones clandestinas en tiempos de neo-movilidades alternativas y el muro de Donald Trump. Religación, 4(13), I6-3I.

Baker, B. (20I7). Immigration Enforcement Actions: 20I6. Annual Report. Office of Immigration Statistics, DHs, December, I-II.

Baltazar, A.I. (20I4). Vivir de Paso y mirando al Norte. Identidades y comunidades móviles y contingentes en el tránsito migratorio centroamericano. Tesis de Maestría, Estudios Culturales. Tijuana, Baja California: El Colef.

Casillas, R. (199I). Migraciones centroamericanas en México. Semblanza de un proceso social emergente. Relaciones. Estudios de Historia y Sociedad, XII(46), 67-8I.

Casillas, R. (2006). Una vida discreta, fugaz y anónima: los centroamericanos transmigrantes en México. 28 de marzo de 20I9. <http:// www.elfaro.net/templates/elfaro/migracion/vida.pdf $>$.

Castillo, D. (1983). Centroamérica: más allá de la crisis. México: SIAP. 
Castillo, M.A., Lattes, A. y Santibáñez, J. (coords., 1998). Migración y fronteras. México: El Colef, Asociación Latinoamericana de Sociología, Colmex.

Castillo, M.A. (2000). Las políticas hacia la migración centroamericana en países de origen, destino y de tránsito. Papeles de Población, 6(24), abril-junio, I33-I57.

CBP. Customs and Border Protection (20I7). United States Border Patrol Southwest Family Unit Subject and Unaccompanied Alien Children Apprehensions Fiscal Year 2016. Newsroom. DHS. 2I-2-2020: <https:// www.cbp.gov/newsroom/stats/southwest-border-unaccompanied-children/fy-20I6>.

СвP (20I8). Statement of Commissioner Kevi McAleenan U.S. Customs and Border Protection Joint Press Conference with Nortcom. Newsroom. DHs. 29 de octubre. <https://www.cbp.gov/news$\mathrm{room} /$ speeches-and-statements/statement-commissioner-kevin-mcaleenan-us-customs-and-border>.

свр (2019). U.S. Border Patrol Southwest Border Apprehensions by Sector. Newsroom. <https://www.cbp.gov/newsroom/stats/usbp-sw-border-apprehensions $>$.

Coello, L.M. (2019). Gobernabilidad por niveles: el caso del flujo de migración haitiano en América. Migraciones Internacionales, IO. <http://dx.doi.org/I0.33679/rmi.viir.2I55>.

Cordero, B. y C. Figueroa (20II). Triturando a la humanidad: capitalismo, violencia y migración en el tránsito por México. En D. Villafuerte y M. del C. García (coords.). Migración, seguridad, violencia y derechos humanos. Lecturas desde el sur. México: Porrúa.

Cortina, A. (20I7). Aporofobia, el rechazo al pobre. Un desafío para la democracia. Barcelona: Paidós.

Cruz de Echeverría, S. (20I4). El norte en la mira. Imaginarios y cultura de migración en Jalpan de Serra, Querétaro. Tesis de Maestría en Estudios Culturales. Tijuana: El Colef. I2 diciembre de 20I4: <https://colef.repositorioinstitucional.mx/jspui/bitstream/IOI4/I24/I/TESIS\%2O-\%2OCruZ\%2Ode\%2OEcheverria\%2O Loebell\%2oStephanie.pdf>. 
DHS (2016). Statement by Secretary Johnson on Southwest Border Security. DHS Press Office, October, 17. 24 de febrero del 2020: <https://www.dhs.gov/news/20I6/Io/I7/statement-secretary-johnson-southwest-border-security>.

Durand, J. and Massey, D.S. (2019). Debacles on the Border: Five Decades of Fact-Free Immigration Policy. The Annals of the American Academy of Political and Social Science, 684(I), 6-20.

Durand, J. (2020). Triángulo Norte. La Jornada. México. Consultado el 20-2-2020: »https://www.jornada.com.mx/2020/oi/19/opinion/or6a2pol>.

ECLAC. Economic Commission for Latin America and Caribbean (2006). International Migration, Human Rights and Development in Latin America and the Caribbean: Summary and Conclusions. Documento Cepal. <https://repositorio.cepal.org/bitstream/handle/II362/13I4I/So600007_en.pdf?sequence=I>.

Fernández, M. (20I8). En la frontera con la Guardia nacional: 'Otro par de ojos y oídos'. New York Times, edición en español, i8 de abril. I8 de abril de 20I8: <https://www.nytimes.com/es/2018/o4/I8/ frontera-guardia-nacional-trump-mexico/>.

Guo, M. (2020). Immigration Enforcement Actions: 2019. Annual Flow Report. Office of Immigration Statistics, DHs, september 2020. Hernández, M.P. (2019). Salvadoreńos deportados desde Estados Unidos: procesos de post-deportación y reinserción socio-laboral en el «lugar» de origen. Tesis de Doctorado, Estudios de Migración. Tijuana: El Colef.

Hirschfeld, J. (20I8). Trump envía 5200 efectivos a la frontera con México por caravana migrante. New York Times, edición en español, 29 de octubre. <https://www.nytimes.com/es/2018/Io/29/ trump-tropas-frontera-caravana/>.

Hirschfeld, J. y E. Sullivan (20I8). Trump propone que militares resguarden la frontera. New York Times, edición en español, 3 de abril. <https://www.nytimes.com/es/2018/o4/o3/trump-militares-frontera-migrantes/>.

ICE. Immigration and Customs Enforcement (2018). Fiscal Year 2017 ICE Enforcement and Removal Operations Report. DHs. <https://www. 
ice.gov/sites/default/files/documents/Report/20I7/iceEndOfYearFY20I7.pdf>.

ICE (202I). U.S. Immigration and Customs Enforcement Fiscal Year 2020. Enforcement and Removal Operations Report. DHs. <https://www. ice.gov/doclib/news/library/reports/annual-report/eroReportFY2020.pdf>.

INM (2019). Coordina Instituto Nacional de Migración acciones interinstitucionales para dar la bienvenida a la Caravana de Paisanos 2019. INM, Boletín No. 370/2019. <https://www.gob.mx/inm/ prensa/coordina-instituto-nacional-de-migracion-acciones-interinstitucionales-para-dar-la-bienvenida-a-la-caravana-de-paisanos-2019-230227? idiom=es $>$.

Izcara, S. (20I7). Migrant smuggling on Mexico's Gulf Route: The Actors Involved. Latin American Perspectives, 44(6), I6-30.

Menjívar, C. (2000). Fragmented Ties: Salvadoran Immigrant Networks in America. Usa: University of California Press.

Mexa Institute (2019a). Mexicanos en Estados Unidos. Los datos más recientes a marzo de 20I9. Mexa Fact. Washington, D. C. <http:// mexainstitute.org/wp-content/uploads/20I9/o8/Boletin-ESP-Estadisticas-190523.pdf>.

Mexa Institute (2019b). Por qué los centroamericanos emigran y por qué no dejarán de hacerlo pronto. Mexa Fact. Washington, D. C. $<$ http://mexainstitute.org/wp-content/uploads/2019/og/Boletin-ESP-Centroamerica-Breve-09-I.pdf>.

Noe-Bustamante, L. (2019). Key Facts About U.S. Hispanics and Their Diverse Heritage. PEw Research Center. <https://www.pewresearch.org/fact-tank/2019/og/ı6/key-facts-about-u-s-hispanics/>.

Pastor, R. (1988). Historia de Centroamérica. México: El Colegio de México.

Petersen, W. (1979). Migración. Aspectos Sociales. Enciclopedia Internacional de las Ciencias Sociales. Madrid: Aguilar.

Rushdie, S. (2003). Step Across this Line. Collected Non-fiction 1992-2002. Nueva York: Modern Library. 
Ruiz, O. (200I). Los riesgos de cruzar. La migración centroamericana en la frontera México-Guatemala. Frontera Norte, I3(25) 7-4I.

Ruiz, O. (20I7). La deportación y la separación familiar en la frontera San Diego- Tijuana. Culturales, I (29), I2I-I49.

Sánchez, V. (1993). Matamoros-sur de Texas: el tránsito de los migrantes de América Central por la frontera México-Estados Unidos. Estudios Sociológicos, XI(3I), I83-207.

Sánchez, G. (20I8). Topan con el muro. Frontera, I4 de noviembre. <https://www.frontera.info/Noticias/2018/II/I4/I387527-Topan-con-el-muro.html>.

Semple, K. (20I7). México: de país de tránsito a nación refugio. New York Times, I3 de febrero. <https:/www.nytimes.com/es/20I7/o2/13/ mexico-de-pais-de-transito-a-nacion-refugio/>.

Semple, K. (20I8a). Los tuits de Trump convierten al Viacrucis Migrante en un asunto internacional. New York Times, edición en español, 3 de abril. <https://www.nytimes.com/es/2018/04/o3/trump-caravana-migrante/>.

Semple, K. (20I8b). Así es la caravana migrante criticada por Trump. New York Times, edición en español, 5 de abril. <https://www. nytimes.com/es/2018/04/o5/caravana-trump-mexico/>.

Semple, K. (20I8c). Trump Threatens to Punish Honduras Over Immigrant Caravan. New York Times, I6 de octubre. <https://www. nytimes.com/2018/Io/I6/world/americas/trump-immigrant-caravan. html?action $=$ click $\&$ module $=$ RelatedCoverage $\&$ pgtype $=$ Article $\&$ region $=$ Footer $>$.

Semple, K. (2018d). What is the Migrant Caravan and Why Does Trump Care? New York Times, I8 de octubre. <https://www.nytimes. com/20I8/Io/I8/world/americas/trump-migrant-caravan.html?module $=$ inline $>$.

Torres-Rivas, E. (2012). ¿Valió la pena?: guerras civiles y democracia en Centroamérica. Nueva Sociedad, 240, I49-62.

unODC (2012). Delincuencia organizada transnacional en Centroamérica y el Caribe: una evaluación de las amenazas. <https://www.unodc. org/documents/data-and-analysis/Studies/TOC_Central_America_and_the_Caribbean_spanish.pdf $>$. 
Varela, A. (20I3). Del silencio salimos: la Caravana de madres hondureñas en México. Un ejemplo de resistencias en clave femenina al régimen global de fronteras. En A. Aquino, F. Decosse y A. Varela (coords.). Desafiando fronteras. Control de la movilidady experiencias migratorias en el contexto capitalista. México: Sur+, I75-I86.

Varela, A. (2016). El Movimiento Migrante Mesoamericano. Una aproximación desde la sociología de la acción colectiva a un ejemplo de luchas migrantes. Amnis Revue de civilisation contemporaine Europes/Amériques. <http://amnis.revues.org/2854>.

Witsman, K. (2019). Immigration Enforcement Actions: 2017. Annual Report. Office of Immigration Statistics, DHS, march, I-I4.

Wu, A. (2006). Border Apprehensions: 2005. Fact Sheet. Office of Immigration Statistics, DHs, november, I-2.

Ximénez, P. (20I8). La caravana de migrantes desborda los recursos de San Diego. El Pais, I de mayo. <https://elpais.com/internacio$\mathrm{nal} / 2018 / 04 / 30 /$ actualidad/I525I06719_905175.html>. 